\title{
"PROCESOS TERRITORIALES RELACIONADOS CON
}

LA EXPANSIÓN URBANA. MOVIMIENTOS DE POBLACIÓNY

- DESPLAZAMIENTO DE USOS PRODUCTIVOS

- EN EL GRAN CORRIENTES"

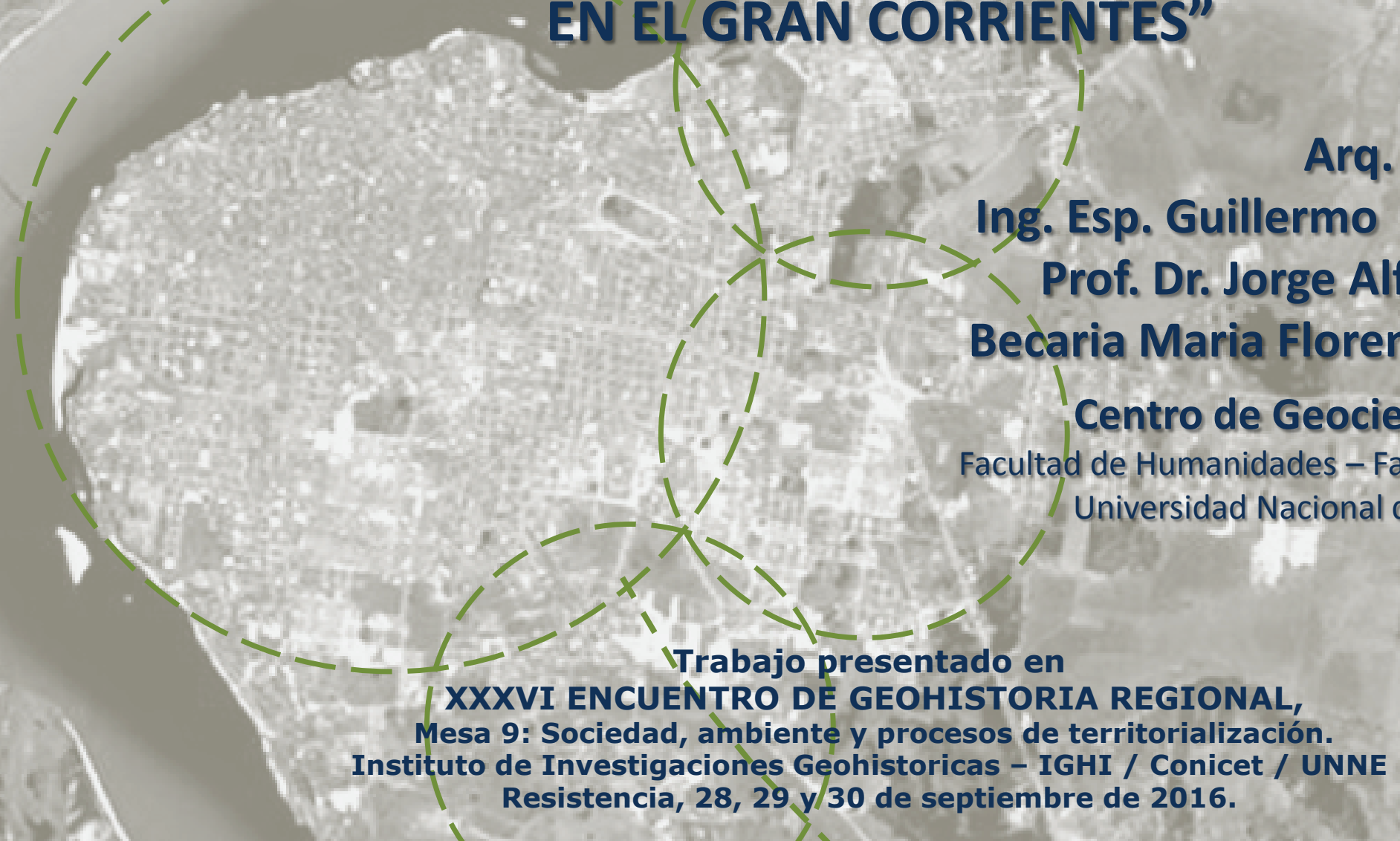

Publicado en formato digital: Arq. Silvina López; Ing. Guillermo Antonio Arce; Prof, Dr. Jorge Alfredo Alberto, Becaria Maria Florencia Medrano. PROCESOS TERRITORIALES RELACIONADOS CON LA EXPANSIÓN URBANA. MOVIMIENTOS DE POBLACIÓN Y DESPLAZAMIENTO DE USOS PRODUCTIVOS EN EL GRAN CORRIENTES. Revista Geográfica Digital. IGUNNE. Facultad de Humanidades. UNNE. Año 13. № 26. Julio - Diciembre 2016. ISSN 1668- 5180 Resistencia, Chaco. En: http:/4hum.unne.edu.ar/revistas/geoweb/default.htm 


\section{ENCUENTRO DE GEOHISTORIA REGIONAL}

Instituto de Investigaciones Geohistoricas - IGHI / Conicet / UNNE

Resistencia, 28, 29 y 30 de septiembre de 2016.

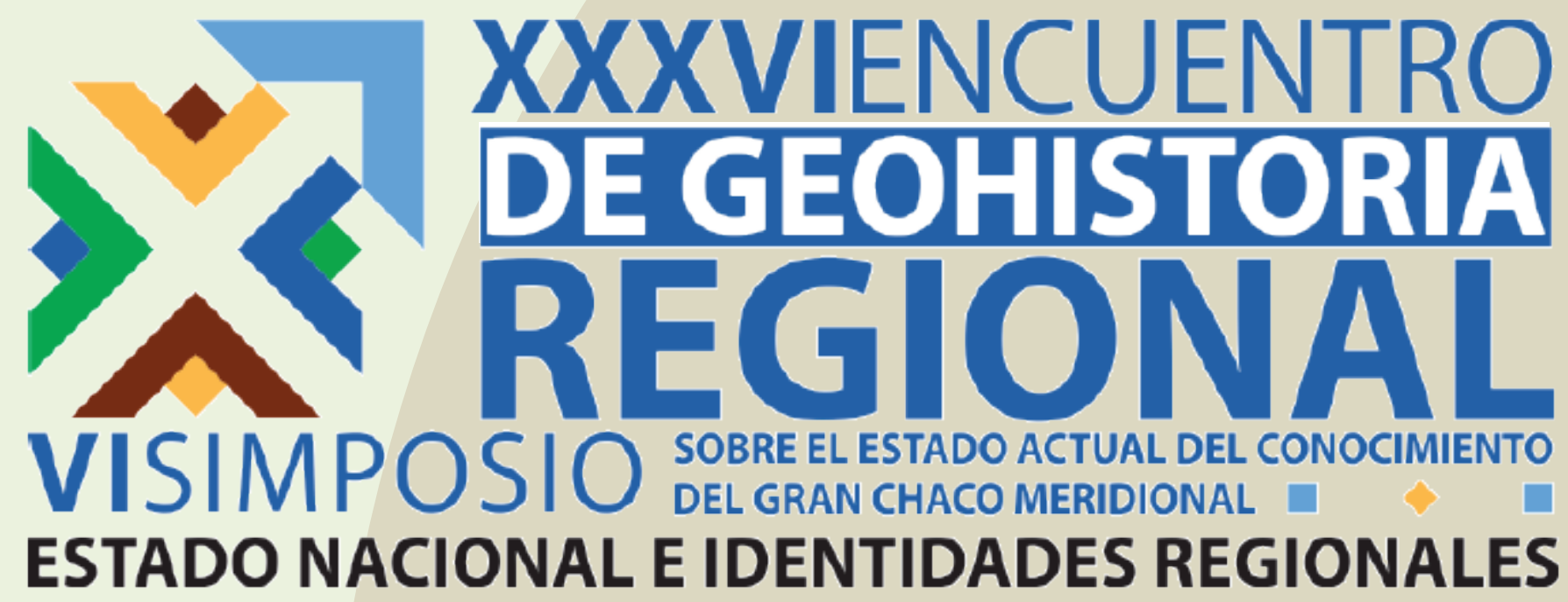

Publicado en formato digital: Arq. Silvina López; Ing. Guillermo Antonio Arce; Prof. Dr. Jorge Alfredo Alberto, Becaria Maria Florencia Medrano. PROCESOS TERRITORIALES RELACIONADOS CON LA EXPANSIÓN URBANA. MOVIMIENTOS DE POBLACIÓN Y DESPLAZAMIENTO DE USOS PRODUCTIVOS EN EL GRAN CORRIENTES. Revista Geográfica Digital. IGUNNE. Facultad de Humanidades. UNNE. Año 13. № 26. Julio - Diciembre 2016. ISSN 1668- 5180 Resistencia, Chaco. En: http://hum.unne.edu.ar/revistas/geoweb/default.htm 
Esta presentación forma parte de la exposición resumida de un trabajo publicado en el XXXVI Encuentro de Geohistoria Regional organizadas por investigadores del Instituto de Investigaciones Geohistoricas - IGHI / Conicet / UNNE, Resistencia, 28, 29 y 30 de septiembre de 2016 .

\section{Objetivo:}

Divulgar -en forma breve- en la comunidad académica y en la sociedad en general, trabajos realizados y expuestos en eventos para especialistas, que de otra forma no llegarán a diferentes interesados en estos temas, en especial a los que no han podido asistir a estos eventos.

\section{Titulo:}

PROCESOS TERRITORIALES RELACIONADOS CON LA EXPANSIÓN URBANA. MOVIMIENTOS DE POBLACIÓN Y DESPLAZAMIENTO DE USOS PRODUCTIVOS EN EL GRAN CORRIENTES.

\section{Autor/es:}

Arq. López, Silvina, silvina_lopez@hotmail.com;

Ing. Arce, Guillermo Antonio, gar_arce@yahoo.com.ar;

Prof. Dr. Alberto, Jorge Alfredo, jaalberto@hotmail.com,

Becario: Medrano, Maria Florencia

Centro de Geociencias Aplicadas.

Facultad de Humanidades - Facultad de Ingeniería.

Universidad Nacional del Nordeste - UNNE 


\section{Titulo:}

\section{PROCESOS TERRITORIALES RELACIONADOS CON LA EXPANSIÓN URBANA. MOVIMIENTOS DE POBLACIÓN Y DESPLAZAMIENTO DE USOS PRODUCTIVOS EN EL GRAN CORRIENTES.}

\section{Resumen:}

El trabajo se enmarca en un proyecto de investigación sobre la aplicación de Geoindicadores al estudio de los usos del suelo del área conformada por el Gran Resistencia, el Gran Corrientes, y sus áreas de influencia (PI H012/14 SGCyT/UNNE) En estas áreas metropolitanas, los territorios sujetos al proceso de urbanización abarcan una superficie con una extensión radial de entre diez y cincuenta kilómetros alrededor de las ciudades, en la cual se dan diferentes usos de suelo configurando un mosaico de usos urbanos y productivos que coexisten con los ecosistemas naturales.

El presente análisis se centra en la ciudad capital de Corrientes y su área de influencia, que conforma un sistema de asentamientos urbanos y rurales que sufre las presiones de los procesos de expansión de la misma. En ese marco, este trabajo estudia la vinculación entre la dinámica de urbanización y los procesos territoriales, con énfasis en los movimientos de población y el desplazamiento de usos productivos por actividades urbanas, con serios desequilibrios sociales y ambientales.

Palabras clave: Crecimiento urbano, geoindicadores, procesos territoriales, usos productivos. 


\section{INTRODUCCIÓN A LA PROBLEMÁTICA DE ESTUDIO} LA EXPANSIÓN URBANA. MOVIMIENTOS DE POBLACIÓN Y DESPLAZAMIENTO DE USOS PRODUCTIVOS EN EL GRAN CORRIENTES. Revista Geográfica Digital. IGUNNE. Facultad de Humanidades. UNNE. Año 13. № 26. Julio - Diciembre 2016. ISSN 1668- 5180 Resistencia, Chaco. En: http://hum.unne.edu.ar/revistas/geoweb/default.htm 
El trabajo se enmarca en un proyecto de investigación sobre la aplicación de Geoindicadores al estudio de los usos del suelo del área conformada por el Gran Resistencia, el Gran Corrientes, y sus áreas de influencia (PI $\mathrm{n}^{\circ}$ H012/14 SGCYT/UNNE)

Uno de los objetivos del proyecto es desarrollar indicadores que reflejen la dinámica territorial, relacionada con procesos de localización y urbanización, y monitorear la modificación de los usos del suelo del área periurbana y rural.

El trabajo analiza la vinculación entre la dinámica de urbanización y los procesos territoriales, con énfasis en los movimientos de población y el desplazamiento de usos productivos por actividades urbanas.

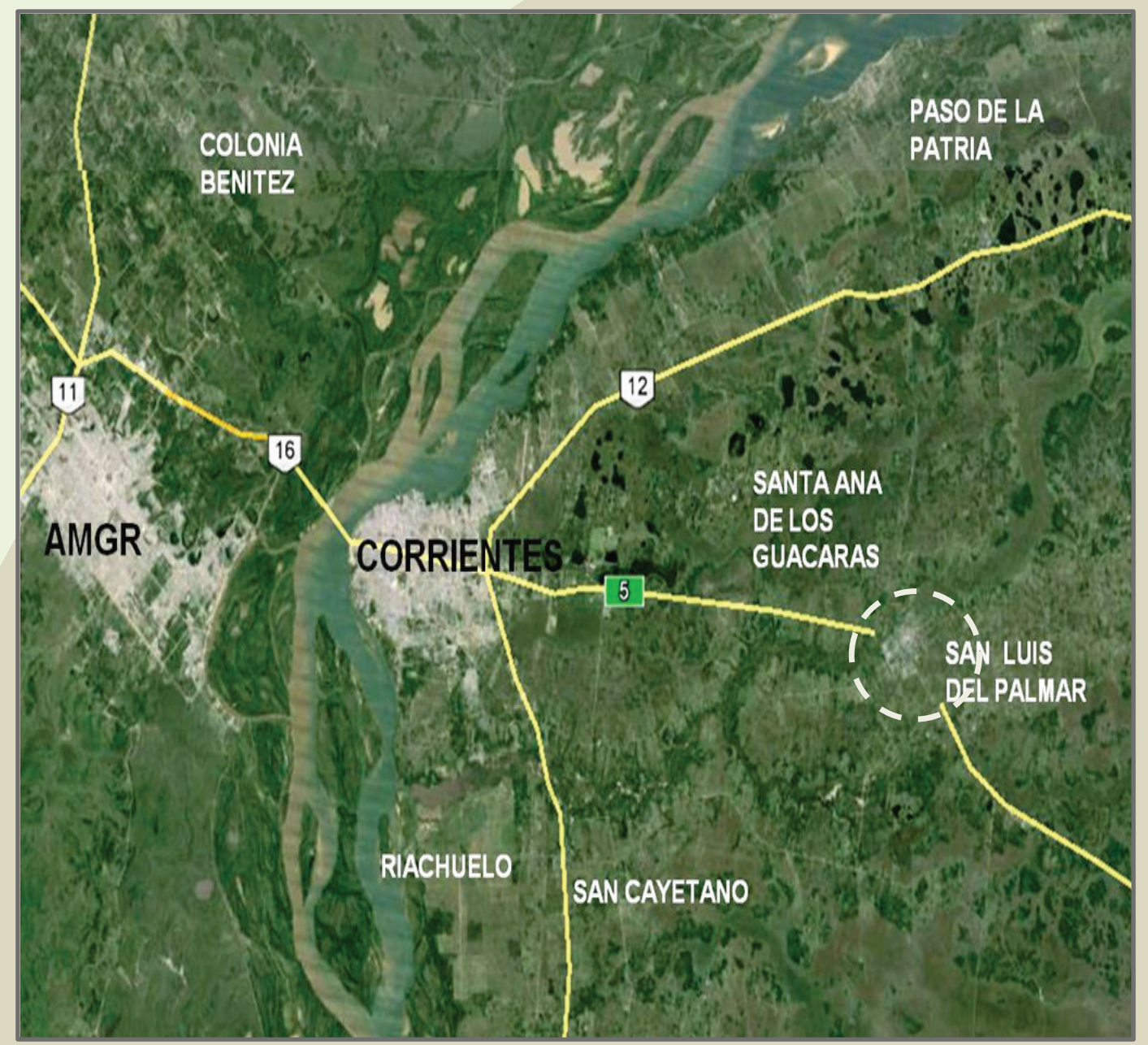
Humanidades. UNNE. Año 13. № 26. Julio - Diciembre 2016. ISSN 1668- 5180 Resistencia, Chaco. En: http://hum.unne.edu.ar/revistas/geoweb/default.htm 
Los asentamientos que conforman el sistema urbano del área, se originaron en la estructura del territorio colonial, y su desarrollo fue condicionado por esa estructura y por su rol marginal en los esquemas posteriores de organización política y espacial del territorio argentino.
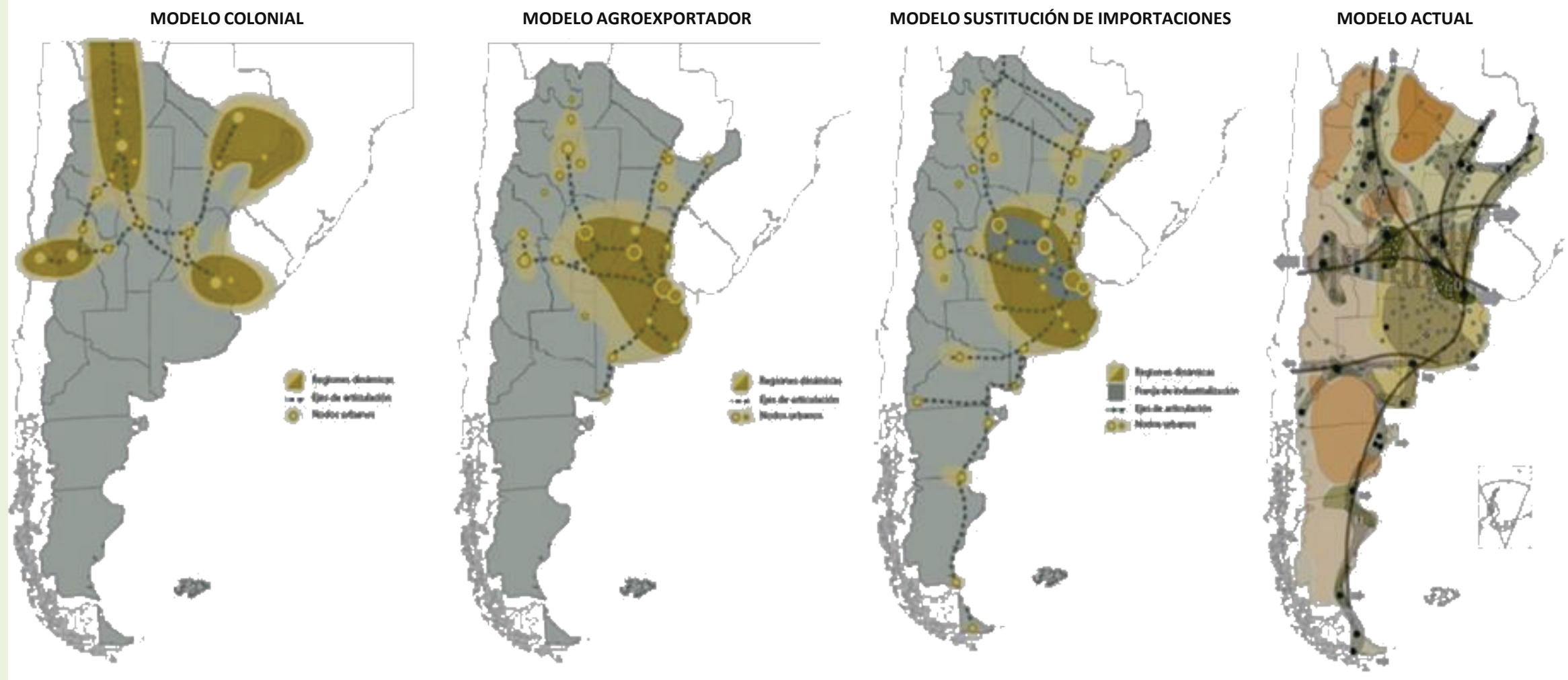

Fuente: Ministerio de Planificación Federal, Inversión Pública y Servicios (2011). “Plan Estratégico Territorial Avance II: planificación estratégica territorial. ........". 1a ed. Buenos Aires: Ministerio de Planificación Federal, Inversión Pública y Servicios. Humanidades. UNNE. Año 13. № 26. Julio - Diciembre 2016. ISSN 1668- 5180 Resistencia, Chaco. En: http://hum.unne.edu.ar/revistas/geoweb/default.htm 
Los territorios sujetos al proceso de urbanización abarcan una superficie con una extensión radial de entre diez y cincuenta kilómetros alrededor de las ciudades, en la cual se dan diferentes usos de suelo configurando un mosaico de usos urbanos y productivos que coexisten con los ecosistemas naturales.

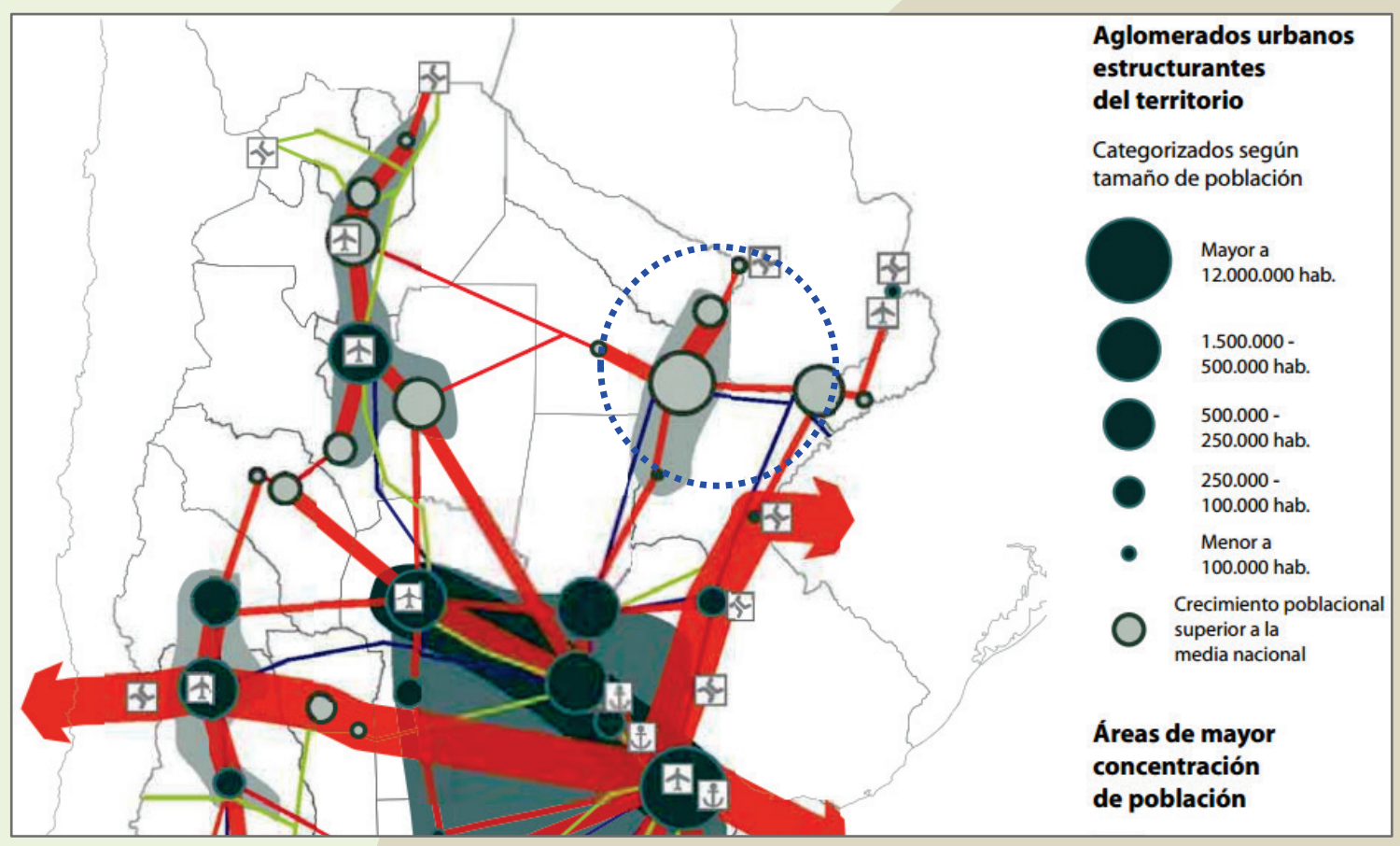

Fuente: Plan Estratégico Territorial. Avances 2008 y 2011

A pesar del gran desequilibrio tanto en cantidad de población como en complejidad de las actividades urbanas, la fuerte interdependencia entre la ciudad capital y el sistema de asentamientos de su área de influencia directa, hace que desde hace tiempo se considere la existencia de un área metropolitana. 


\section{ABORDAJE TEÓRICO METODOLÓGICO} LA EXPANSIÓN URBANA. MOVIMIENTOS DE POBLACIÓN Y DESPLAZAMIENTO DE USOS PRODUCTIVOS EN EL GRAN CORRIENTES. Revista Geográfica Digital. IGUNNE. Facultad de Humanidades. UNNE. Año 13. № 26. Julio - Diciembre 2016. ISSN 1668- 5180 Resistencia, Chaco. En: http://hum.unne.edu.ar/revistas/geoweb/default.htm 
Los territorios y las regiones son concebidos como estructuras dinámicas, en transformación, que están constituyéndose permanentemente a través de las prácticas materiales y culturales de la sociedad (Benedetti, 2008)

Son condicionantes de la acción de las sociedades territoriales: el modo de producción dominante en la escala del sistema internacional; el sistema político, responsable de las formas específicas de impacto del modo de producción; pero también los impactos de los modos de producción precedentes y de los momentos anteriores del modo de producción actual (Santos, 1990)

Los cambios en la distribución espacial de la actividad económica y demográfica no son necesariamente convergentes, "actividades menos productivas, como la agricultura campesina, tienen una más fuerte influencia en la distribución espacial de la población (...) , el impacto de corto plazo es menos visible que el de largo plazo y las transformaciones socio-espaciales tenderán a ser más estables y duraderas..." (Cuervo González, 2005) 
Las definiciones de ciudad metropolitana en general coinciden en que se trata de un sistema de asentamientos numeroso que puede ser físicamente continuo o discontinuo, pero funcionalmente vinculado entre sí como conjunto; en el que se puede identificar ámbitos específicos de organización urbana con un relativo grado de autonomía.

En el caso de la discontinuidad física, aparece la complejidad de los espacios de transición entre lo urbano y lo rural, "...la explicación de lo urbano y lo rural se da como si fueran dos lugares concretos, con cierta independencia, sin reconocer totalmente el ámbito donde se manifiestan las hibridaciones, los aculturamientos, los modos de vida, el intercambio de flujos y el desarrollo de nuevas funciones, lo que generalmente se conoce como periurbano...." (Ávila Sánchez, 2005)

"áreas metropolitanas incipientes", ámbitos en los que los procesos metropolitanos están en una fase de inicio y tienen una limitada materialización debido a la escasa entidad poblacional y funcional de la ciudad central o del sistema de asentamientos, que no posibilitan procesos metropolitanos significativos (Feria, 2011)

\section{La movilidad residencial constituiría un factor más determinante en el alcance y conformación de las dinámicas espaciales metropolitanas... (Feria, 2011: 46)}




\section{ESCALA ESPACIAL}

En las áreas metropolitanas, los territorios sujetos al proceso de urbanización abarcan una superficie con una extensión radial de entre diez y cincuenta kilómetros, en la cual se dan diferentes usos de suelo configurando un mosaico de usos urbanos y productivos que coexisten con los ecosistemas naturales.

El análisis se centra en la ciudad capital de Corrientes y su área de influencia, que conforma un sistema de asentamientos urbanos y rurales que sufre las presiones de los procesos de expansión de la misma.

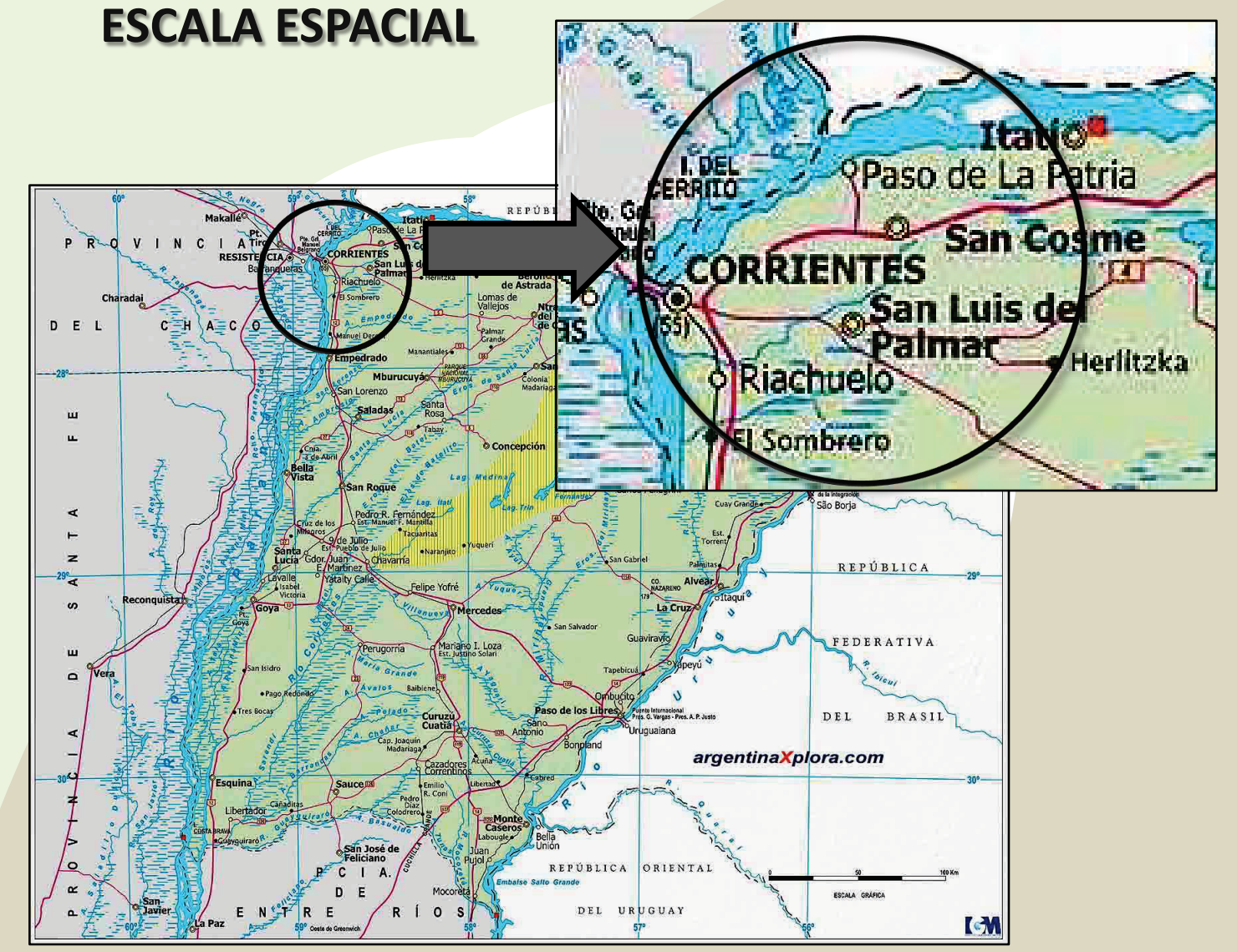

Se toma para el análisis el área formada por los Departamentos

Capital (municipios Corrientes y Riachuelo),

San Cosme (municipios San Cosme, Santa Ana y Paso de la Patria) y

San Luis del Palmar (municipios San Luis del Palmar y Herlitzka). 


\section{ESCALA TEMPORAL}

Los cortes temporales se toman con base en las etapas de la historia económica argentina establecidas por Rapoport en función de los cuales se analiza la localización y evolución de la población en el área de estudio, considerando fundamentalmente la cantidad de habitantes y de población urbana y rural.

\section{EVOLUCION HISTORICO -TERRITORIAL}

1. El territorio colonial y los primeros años de vida independiente (hasta 1879)

2. Etapa del modelo agro-exportador (1880-1930)

3. Etapa del modelo de industrialización sustitutiva de importaciones (1931 -1975)

4. Etapa del modelo rentístico-financiero (1976 - 2001)

5. Periodo 2002 - actualidad 


\section{EVOLUCIÓN HISTÓRICO TERRITORIAL} LA EXPANSIÓN URBANA. MOVIMIENTOS DE POBLACIÓN Y DESPLAZAMIENTO DE USOS PRODUCTIVOS EN EL GRAN CORRIENTES. Revista Geográfica Digital. IGUNNE. Facultad de Humanidades. UNNE. Año 13. № 26. Julio - Diciembre 2016. ISSN 1668- 5180 Resistencia, Chaco. En: http://hum.unne.edu.ar/revistas/geoweb/default.htm 
Se toma como ejes de análisis las entidades poblacionales y funcionales (Feria, 2011) en distintos cortes temporales (Rapoport), resaltando datos de la ciudad Capital y su área de influencia directa. De esta manera nos aproximamos a la noción de espacio construido atendiendo los patrones de los asentamientos y el grado de conectividad entre las localidades (PET 2011)

Entidades poblacionales: localización y evolución de la Población según censos, considerando fundamentalmente la cantidad de habitantes y de población urbana y rural.

Entidades funcionales: Evolución de Actividades; red vial y ferroviaria; movilidad y movilidad residencial.

La noción "medio construido" sintetiza la interrelación entre dos componentes: los patrones de instalación de los asentamientos humanos en el territorio y los niveles de conectividad entre las localidades que estos configuran, entendiendo por esto el universo de infraestructuras y redes de servicios que las vinculan (PET 2011) 


\section{EVOLUCIÓN HISTÓRICO TERRITORIAL DE LA ZONA DE ESTUDIO} LA EXPANSIÓN URBANA. MOVIMIENTOS DE POBLACIÓN Y DESPLAZAMIENTO DE USOS PRODUCTIVOS EN EL GRAN CORRIENTES. Revista Geográfica Digital. IGUNNE. Facultad de Humanidades. UNNE. Año 13. № 26. Julio - Diciembre 2016. ISSN 1668- 5180 Resistencia, Chaco. En: http://hum.unne.edu.ar/revistas/geoweb/default.htm 


\section{POBLACIÓN}

Análisis comparativo según escalas espacial y temporal

\begin{tabular}{|c|c|c|c|c|c|}
\hline $\begin{array}{l}\text { Eje de } \\
\text { análisis }\end{array}$ & $\begin{array}{c}\text { Territorio } \\
\text { colonial - } 1879\end{array}$ & $\begin{array}{c}\text { Modelo agro- } \\
\text { exportador } \\
1880-1930\end{array}$ & $\begin{array}{c}\text { Modelo de } \\
\text { industrialización } \\
1930-1975\end{array}$ & $\begin{array}{l}\text { Modelo } \\
\text { rentístico- } \\
\text { financiero } \\
1976-2001\end{array}$ & 2002 -actualidad \\
\hline $\begin{array}{l}\text { Población } \\
\text { Capital }\end{array}$ & $\begin{array}{l}\text { Censo } 1869 \\
10.799\end{array}$ & $\begin{array}{l}\text { Censo } 1914 \\
30.031\end{array}$ & $\begin{array}{l}\text { Censo } 1970 \\
137.823\end{array}$ & $\begin{array}{l}\text { Censo } 2001 \\
321.902\end{array}$ & $\begin{array}{l}\text { Censo } 2010 \\
352.374\end{array}$ \\
\hline $\begin{array}{l}\text { Población } \\
\text { Área de } \\
\text { estudio }\end{array}$ & $\begin{array}{l}\text { Censo } 1869 \\
21.599\end{array}$ & $\begin{array}{l}\text { Censo } 1914 \\
64.064\end{array}$ & $\begin{array}{l}\text { Censo } 1970 \\
161.032\end{array}$ & $\begin{array}{l}\text { Censo } 2001 \\
358.570\end{array}$ & $\begin{array}{l}\text { Censo } 2010 \\
390.194\end{array}$ \\
\hline $\begin{array}{l}\text { Población } \\
\text { Provincia }\end{array}$ & $\begin{array}{l}\text { Censo } 1869 \\
129.028\end{array}$ & $\begin{array}{l}\text { Censo } 1914 \\
347.055\end{array}$ & $\begin{array}{l}\text { Censo } 1970 \\
564.147\end{array}$ & $\begin{array}{l}\text { Censo } 2001 \\
930.991\end{array}$ & $\begin{array}{l}\text { Censo } 2010 \\
992.595\end{array}$ \\
\hline
\end{tabular}




\section{Análisis comparativo de Población}

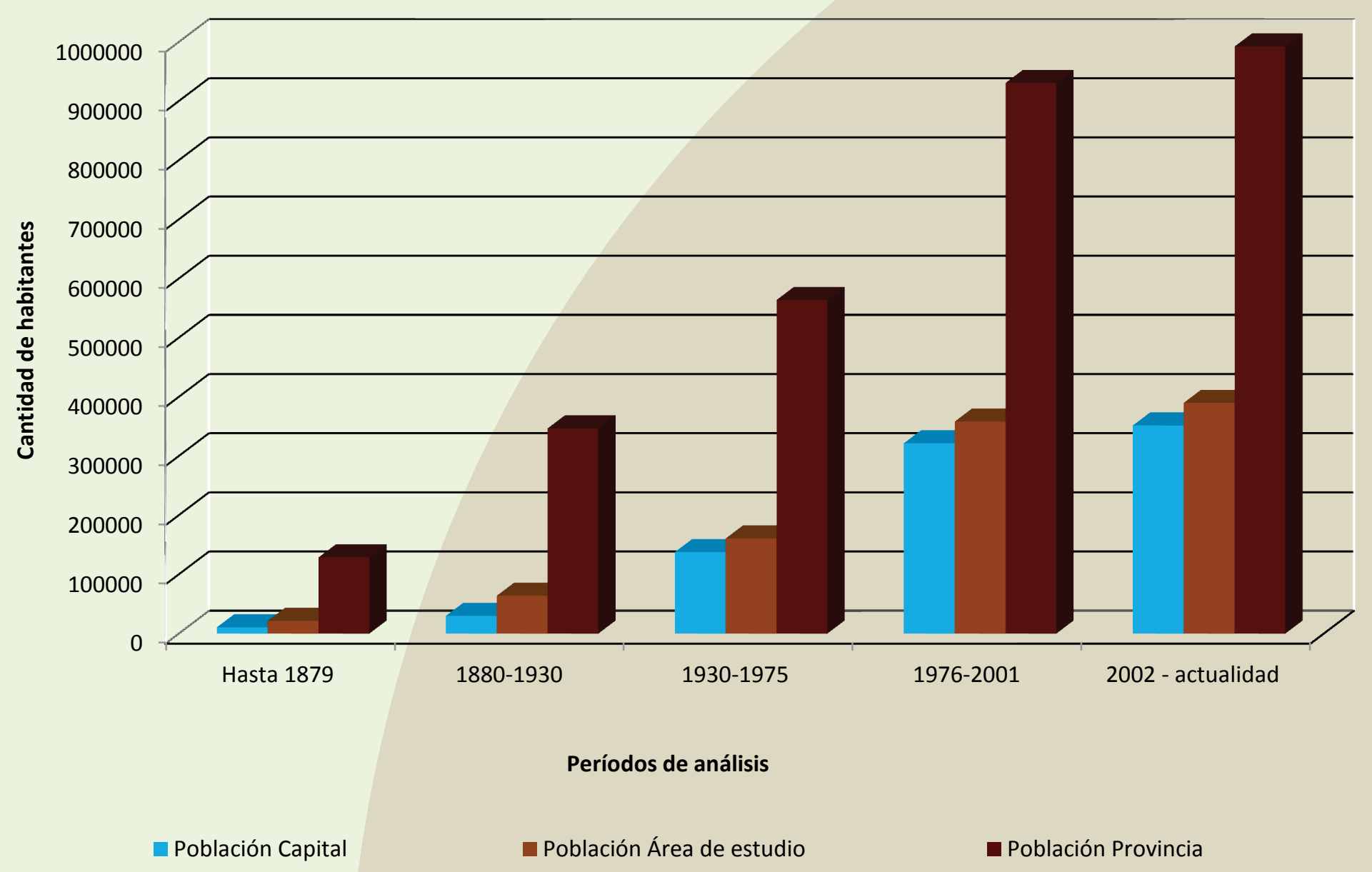

Publicado en formato digital: Arq. Silvina López; Ing. Guillermo Antonio Arce; Prof. Dr. Jorge Alfredo Alberto, Becaria Maria Florencia Medrano. PROCESOS TERRITORIALES RELACIONADOS CON LA EXPANSIÓN URBANA. MOVIMIENTOS DE POBLACIÓN Y DESPLAZAMIENTO DE USOS PRODUCTIVOS EN EL GRAN CORRIENTES. Revista Geográfica Digital. IGUNNE. Facultad de Humanidades. UNNE. Año 13. № 26. Julio - Diciembre 2016. ISSN 1668- 5180 Resistencia, Chaco. En: http://hum.unne.edu.ar/revistas/geoweb/default.htm 


\section{Población total y urbana por Departamento y Municipio 2001 - 2010}

\begin{tabular}{|c|c|c|c|c|}
\hline \multirow{2}{*}{$\begin{array}{l}\text { Departamentos y } \\
\text { Municipios }\end{array}$} & \multicolumn{2}{|c|}{ Censo 2001} & \multicolumn{2}{|c|}{ Censo 2010} \\
\hline & Población total & $\%$ urbana & Población total & $\%$ urbana \\
\hline Dpto. Capital (1) & 328.868 & $97,2 \%$ & 358.223 & $96,7 \%$ \\
\hline Municipio Capital & 321.902 & $97,7 \%$ & 352.374 & $98,3 \%$ \\
\hline Municipio Riachuelo & 3.668 & $0,0 \%$ & 4.218 & $0,0 \%$ \\
\hline Dpto. San Cosme (2) & 13.189 & $26,5 \%$ & 14.381 & $56,7 \%$ \\
\hline Municipio San Cosme & 4.429 & $0,0 \%$ & 4.750 & $53,9 \%$ \\
\hline Municipio Paso de la Patria & 5.818 & $60,1 \%$ & 6.383 & $87,7 \%$ \\
\hline Municipio Santa Ana & 2.942 & $0,0 \%$ & 3.248 & $0,0 \%$ \\
\hline Dpto. San Luis del Palmar (3) & 16.513 & $64,4 \%$ & 17.590 & $69,8 \%$ \\
\hline Municipio San Luis del Palmar & 15.347 & $69,3 \%$ & 17.159 & $71,6 \%$ \\
\hline Municipio Herlitzka & 1.166 & $0,0 \%$ & 431 & $0,0 \%$ \\
\hline Total área $(1+2+3)$ & 358.570 & $91.1 \%$ & 390.194 & $94,0 \%$ \\
\hline TOTAL PROVINCIA & 930.991 & $79,4 \%$ & 992.595 & $92,3 \%$ \\
\hline
\end{tabular}


Se produjo crecimiento de la población urbana en todos los departamentos del área.

En la década del 70 s.XX se alcanza un porcentaje del $80 \%$ de población urbana impulsado fuertemente por el departamento Capital.

En 2010, permanecían rurales los municipios de Santa Ana, Riachuelo y Herlitzka, con estancamiento de la población e incluso disminución en el caso de este ultimo. En el otro extremo, el municipio Capital tiene más del $98 \%$ de la población urbana. 


\section{EVOLUCIÓN DEL PORCENTAJE DE POBLACIÓN URBANA POR DEPARTAMENTO 1914 - 2010}

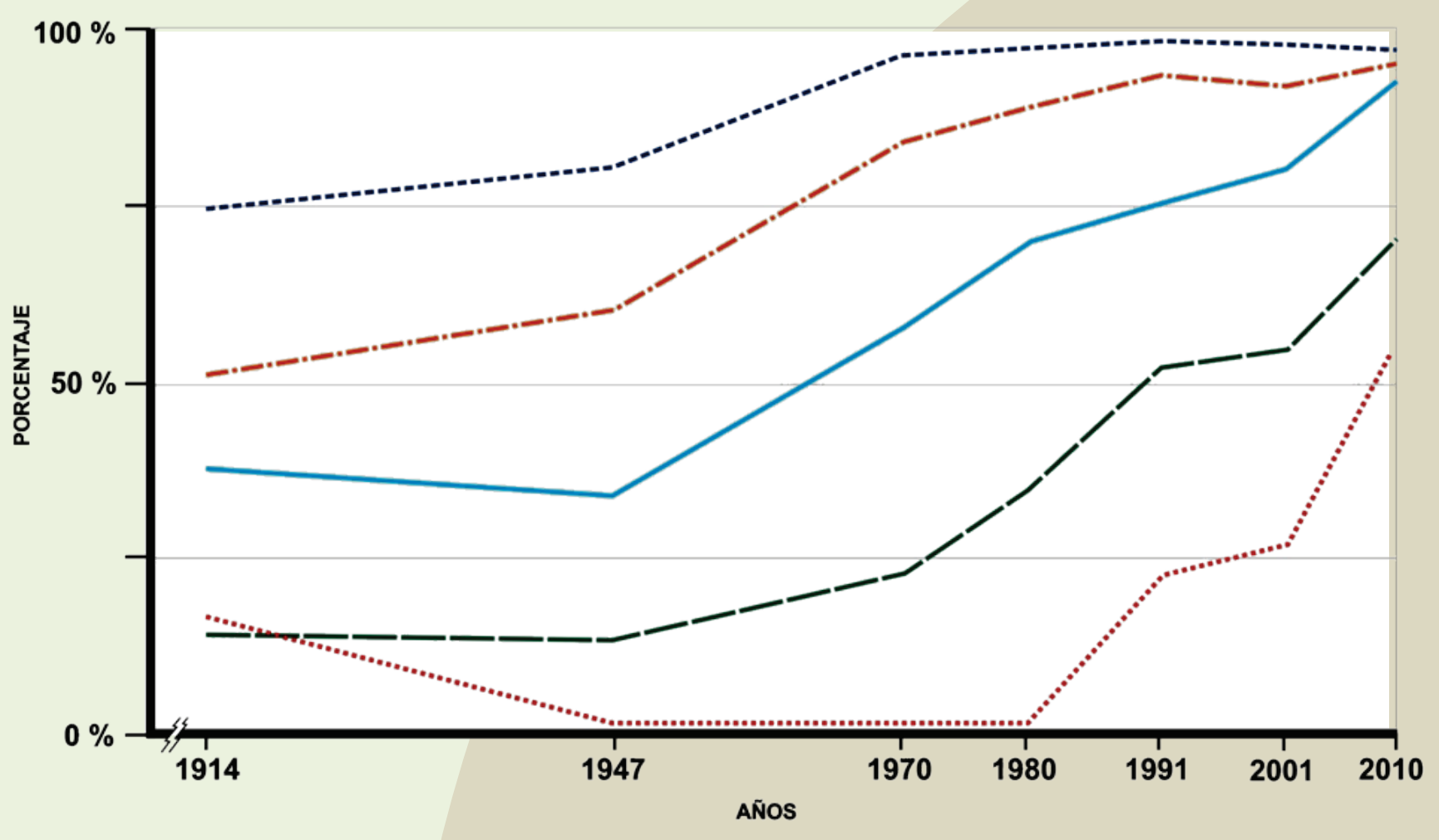

Dpto. Capital

Dpto. San Cosme

\section{Dpto. San Luis del Palmar}

Total área de estudio

Total provincial

Publicado en formato digital: Arq. Silvina López; Ing. Guillermo Antonio Arce; Prof. Dr. Jorge Alfredo Alberto, Becaria Maria Florencia Medrano. PROCESOS TERRITORIALES RELACIONADOS CON LA EXPANSIÓN URBANA. MOVIMIENTOS DE POBLACIÓN Y DESPLAZAMIENTO DE USOS PRODUCTIVOS EN EL GRAN CORRIENTES. Revista Geográfica Digital. IGUNNE. Facultad de Humanidades. UNNE. Año 13. № 26. Julio - Diciembre 2016. ISSN 1668- 5180 Resistencia, Chaco. En: http://hum.unne.edu.ar/revistas/geoweb/default.htm 


\section{ANÁLISIS COMPARATIVO DE CADA EJE SEGÚN ESCALAS ESPACIAL Y TEMPORAL}

\begin{tabular}{|c|c|c|c|c|c|c|}
\hline \multicolumn{2}{|c|}{$\begin{array}{l}\text { Eje de } \\
\text { análisis }\end{array}$} & $\begin{array}{l}\text { Periodo colonial - } \\
\qquad 1879\end{array}$ & $\begin{array}{l}\text { modelo agro-exportador } \\
\qquad 1880-1930\end{array}$ & $\begin{array}{c}\text { modelo de } \\
\text { industrialización } 1930 \text { - } \\
1975\end{array}$ & $\begin{array}{l}\text { modelo rentístico- } \\
\text { financiero } \\
1976-2001\end{array}$ & 2002 - actualidad \\
\hline \multirow{4}{*}{ 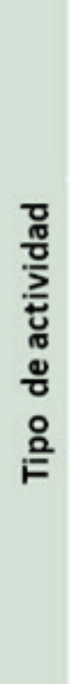 } & $\frac{\bar{\pi}}{\frac{\pi}{0}}$ & $\begin{array}{l}\text { Puerto. Sede } \\
\text { administrativa }\end{array}$ & $\begin{array}{l}\text { Sede de gobierno, administr } \\
\text { Puerto }\end{array}$ & rativa, comercial y financie & & \\
\hline & \multirow{3}{*}{ 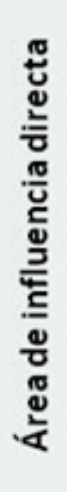 } & \multirow{3}{*}{$\begin{array}{l}\text { Economía de } \\
\text { subsistencia con } \\
\text { fuerte dependencia } \\
\text { de la ciudad de } \\
\text { Corrientes. } \\
\text { Ganadería extensiva }\end{array}$} & \multicolumn{4}{|c|}{ Explotaciones agropecuarias de unidades económicas familiares } \\
\hline & & & \multirow{2}{*}{$\begin{array}{l}\text { Ingenio azucarero y } \\
\text { producción de caña de } \\
\text { azúcar en las colonias }\end{array}$} & \multirow{2}{*}{$\begin{array}{l}\text { Crisis del Ingenio y } \\
\text { transformación en } \\
\text { fabrica de bebidas } \\
\text { alcohólicas }\end{array}$} & \multicolumn{2}{|c|}{$\begin{array}{l}\text { Emprendimientos turísticos y recreativos en Paso } \\
\text { de la Patria, Santa Ana y San Cosme }\end{array}$} \\
\hline & & & & & $\begin{array}{l}\text { Actividades productivas } \\
\text { alternativas }\end{array}$ & $\begin{array}{l}\text { Urbanizacionesy } \\
\text { barrios cerrados en } \\
\text { áreasperi-urbanasy } \\
\text { rurales }\end{array}$ \\
\hline
\end{tabular}
Humanidades. UNNE. Año 13. № 26. Julio - Diciembre 2016. ISSN 1668- 5180 Resistencia, Chaco. En: http://hum.unne.edu.ar/revistas/geoweb/default.htm 


\section{Ingenio Primer Correntino}
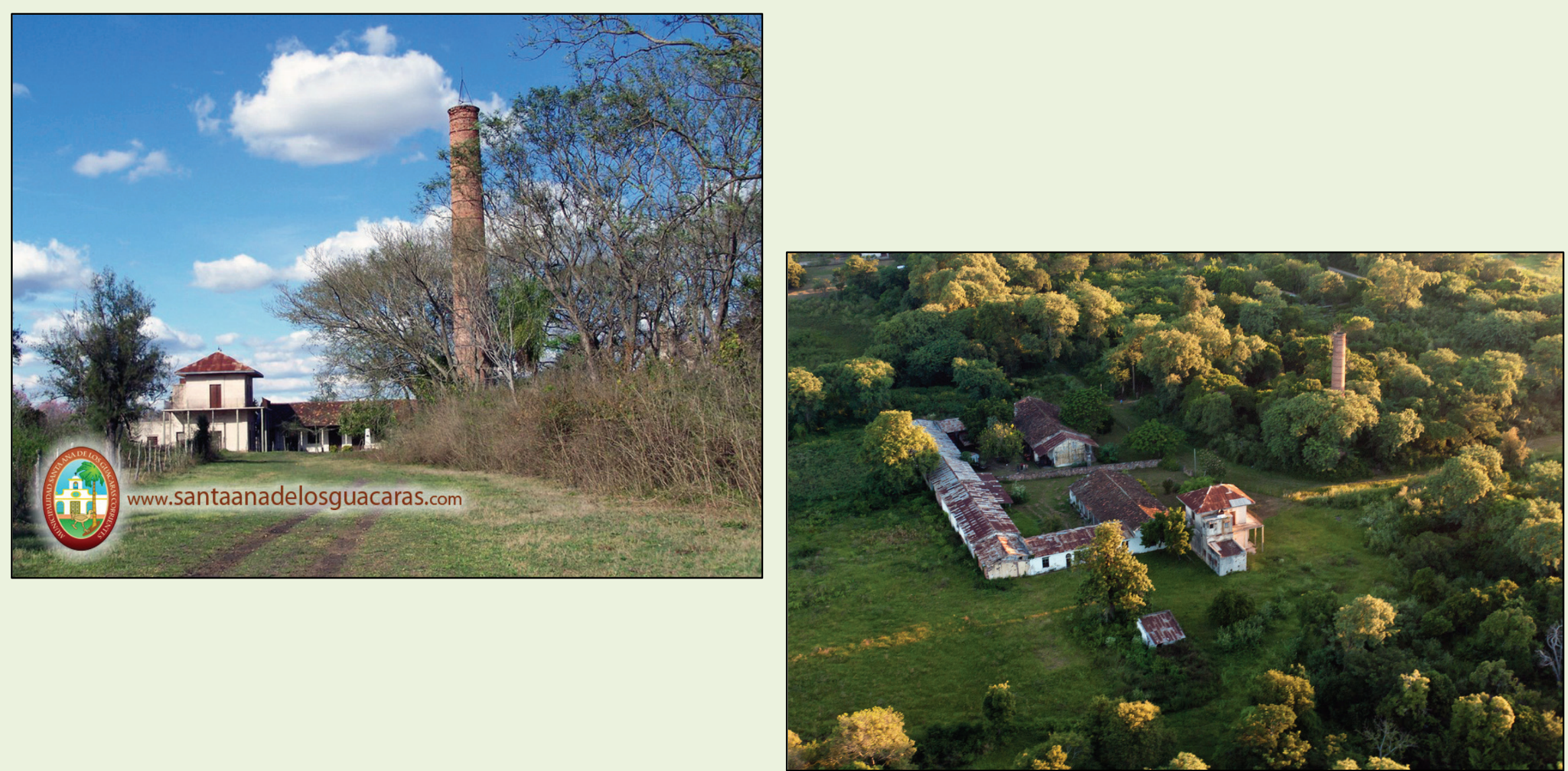

Publicado en formato digital: Arq. Silvina López; Ing. Guillermo Antonio Arce; Prof. Dr. Jorge Alfredo Alberto, Becaria Maria Florencia Medrano. PROCESOS TERRITORIALES RELACIONADOS CON LA EXPANSIÓN URBANA. MOVIMIENTOS DE POBLACIÓN Y DESPLAZAMIENTO DE USOS PRODUCTIVOS EN EL GRAN CORRIENTES. Revista Geográfica Digital. IGUNNE. Facultad de Humanidades. UNNE. Año 13. № 26. Julio - Diciembre 2016. ISSN 1668- 5180 Resistencia, Chaco. En: http://hum.unne.edu.ar/revistas/geoweb/default.htm 


\section{Actividad turística en Área de influencia directa Ciudad Capital}

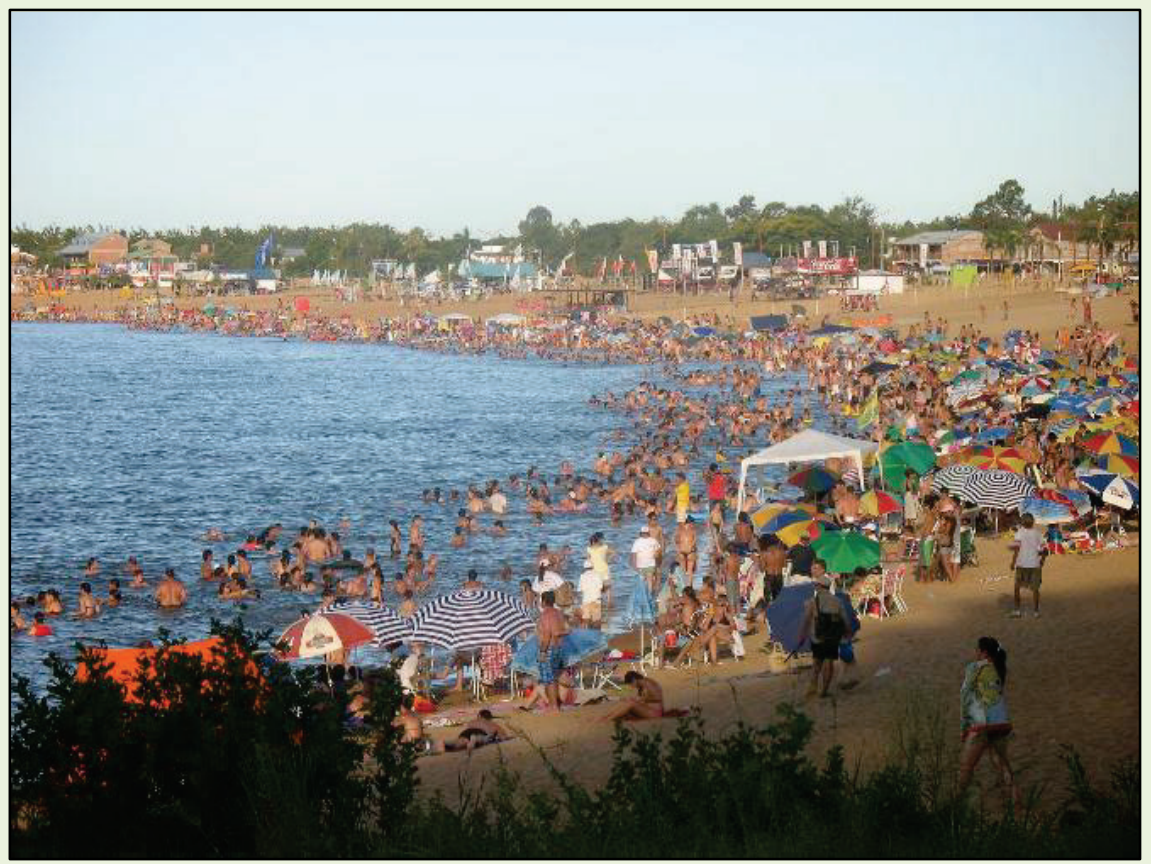
LA EXPANSIÓN URBANA. MOVIMIENTOS DE POBLACIÓN Y DESPLAZAMIENTO DE USOS PRODUCTIVOS EN EL GRAN CORRIENTES. Revista Geográfica Digital. IGUNNE. Facultad de Humanidades. UNNE. Año 13. № 26. Julio - Diciembre 2016. ISSN 1668- 5180 Resistencia, Chaco. En: http://hum.unne.edu.ar/revistas/geoweb/default.htm 


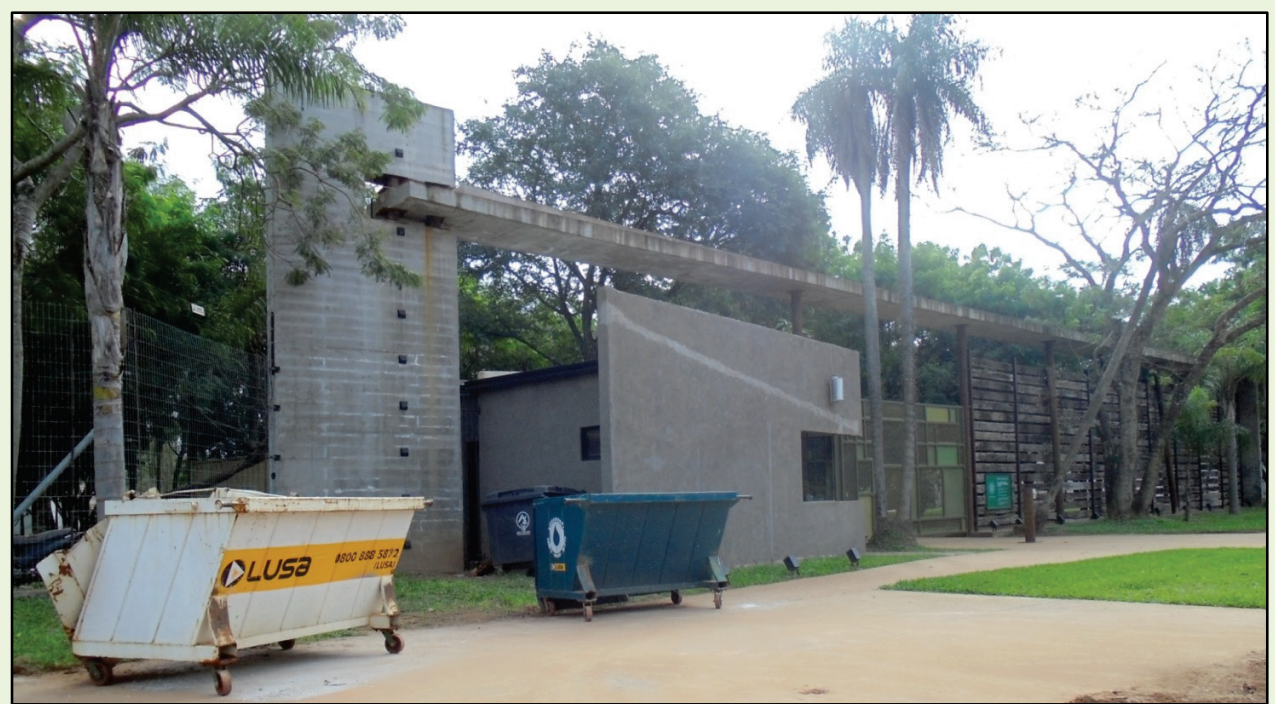

\section{Desarrollos inmobiliarios y actividades productivas en área de influencia directa de la Capital}

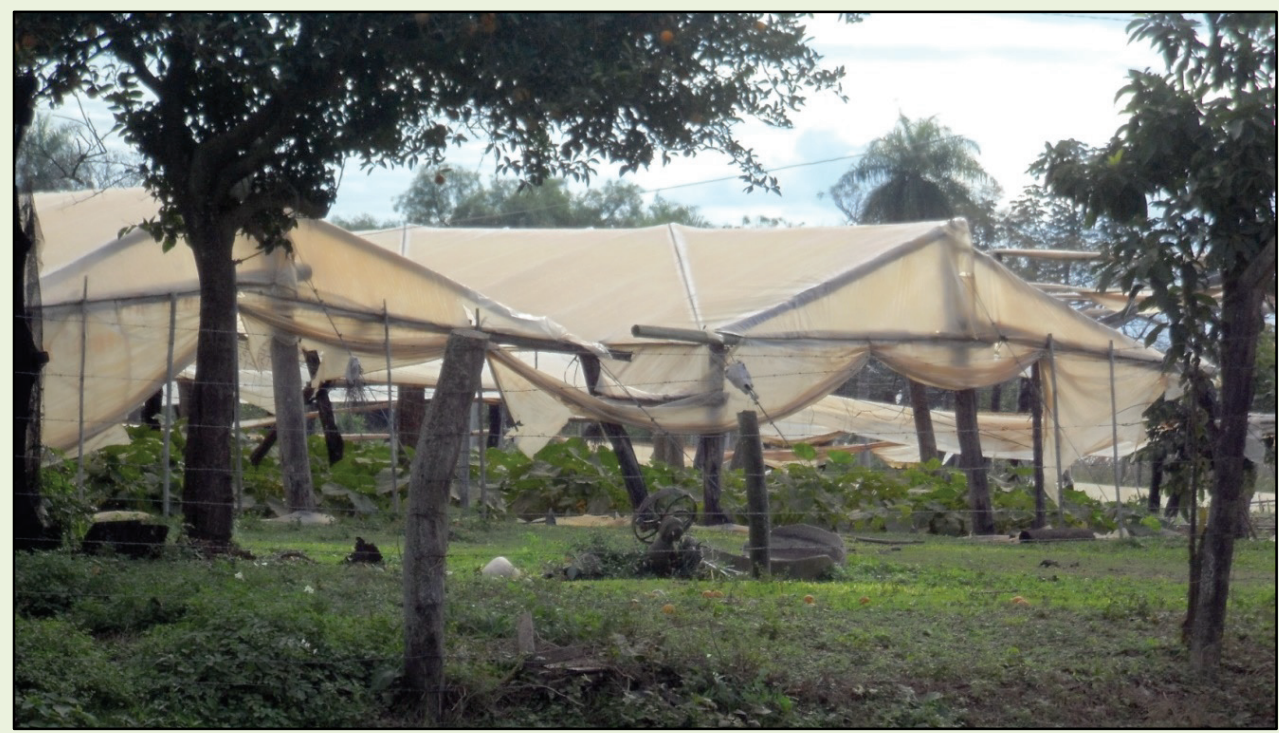

Publicado en formato digital: Arq. Silvina López; Ing. Guillermo Antonio Arce; Prof. Dr. Jorge Alfredo Alberto, Becaria Maria Florencia Medrano. PROCESOS TERRITORIALES RELACIONADOS CON LA EXPANSIÓN URBANA. MOVIMIENTOS DE POBLACIÓN Y DESPLAZAMIENTO DE USOS PRODUCTIVOS EN EL GRAN CORRIENTES. Revista Geográfica Digital. IGUNNE. Facultad de Humanidades. UNNE. Año 13. № 26. Julio - Diciembre 2016. ISSN 1668- 5180 Resistencia, Chaco. En: http://hum.unne.edu.ar/revistas/geoweb/default.htm 


\section{ANÁLISIS COMPARATIVO DE CADA EJE SEGÚN ESCALAS ESPACIAL Y TEMPORAL}

\begin{tabular}{|c|c|c|c|c|c|c|}
\hline \multicolumn{2}{|c|}{$\begin{array}{l}\text { Eje de } \\
\text { análisis }\end{array}$} & $\begin{array}{c}\text { Periodo colonial - } \\
1879\end{array}$ & $\begin{array}{c}\text { modelo agro-exportador } \\
\qquad 1880-1930\end{array}$ & $\begin{array}{c}\text { modelo de } \\
\text { industrialización } 1930 \text { - } \\
1975\end{array}$ & $\begin{array}{c}\text { modelo rentístico- } \\
\text { financiero } \\
1976-2001\end{array}$ & 2002 - actualidad \\
\hline \multirow{5}{*}{ 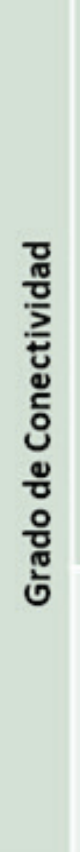 } & \multirow{3}{*}{$\frac{\bar{\pi}}{\frac{\pi}{2}}$} & Red vial lineal & \multicolumn{2}{|l|}{ Red vial integrada incipiente } & \multicolumn{2}{|l|}{ Red vial integrada } \\
\hline & & $\begin{array}{l}\text { Los caminos reales } \\
\text { conectan la Capital } \\
\text { con Santa Ana, San } \\
\text { Cosme y Riachuelo, } \\
\text { pero no las } \\
\text { localidades entre si }\end{array}$ & $\begin{array}{l}\text { Se conecta la Capital con } \\
\text { Santa Ana y San Cosme, } \\
\text { Empedrado y San Luis. Se } \\
\text { conecta Paso de la Patria } \\
\text { con San Luis. }\end{array}$ & $\begin{array}{l}\text { Desarrollo del sistema } \\
\text { vial argentino. Se mejora } \\
\text { la red troncal (RN 12) con } \\
\text { ripio y pavimento }\end{array}$ & $\begin{array}{l}\text { Desarrollo del sistema vial } \\
\text { provincial. Se mejoran las } \\
\text { conexiones entre las } \\
\text { localidades RP } 43,46,3 \text { y } 8\end{array}$ & \\
\hline & & Conectividad baja & \multicolumn{2}{|c|}{ Conectividad media incipiente } & \multicolumn{2}{|l|}{ Conectividad media } \\
\hline & \multirow[t]{2}{*}{ 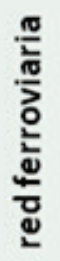 } & & $\begin{array}{l}\text { Red ferroviaria y } \\
\text { ferrocarril económico } \\
\text { unen las localidades }\end{array}$ & $\begin{array}{l}\text { Se inicia la declinación del } \\
\text { sistema ferroviario } \\
\text { argentino }\end{array}$ & $\begin{array}{l}\text { Se produce el abandono } \\
\text { del sistema ferroviario. }\end{array}$ & \\
\hline & & & Conectividadmedia & Conectividad baja & & Sinconed \\
\hline
\end{tabular}
Humanidades. UNNE. Año 13. № 26. Julio - Diciembre 2016. ISSN 1668- 5180 Resistencia, Chaco. En: http://hum.unne.edu.ar/revistas/geoweb/default.htm 
El Gran Corrientes conforma uno de los núcleos estructurantes del territorio nacional y se encuentra dentro de uno de los corredores importantes del país (PET, 2008), y fue categorizado como Nodo Regional de tercer nivel de jerarquía en el Sistema Urbano Nacional por el Programa Argentina Urbana del Plan Estratégico Territorial (PET, 2011)

CAMINOS REALES FINES S. XVIII

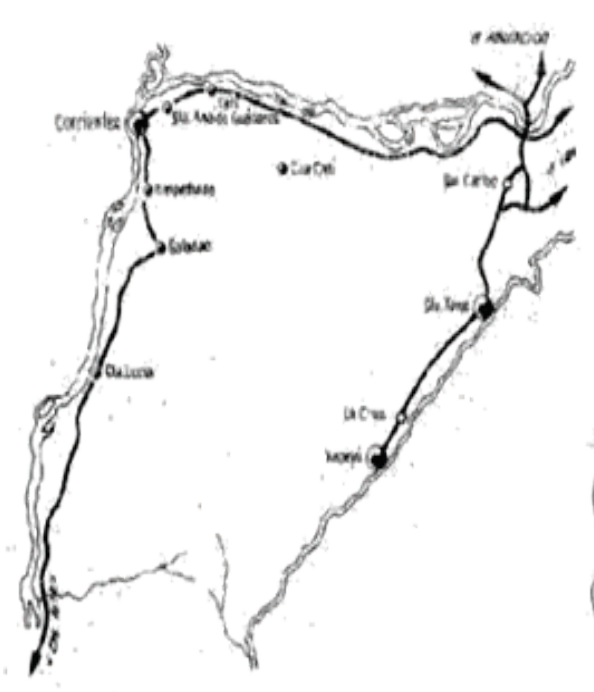

CAMINOS REALES FINES S. XIX

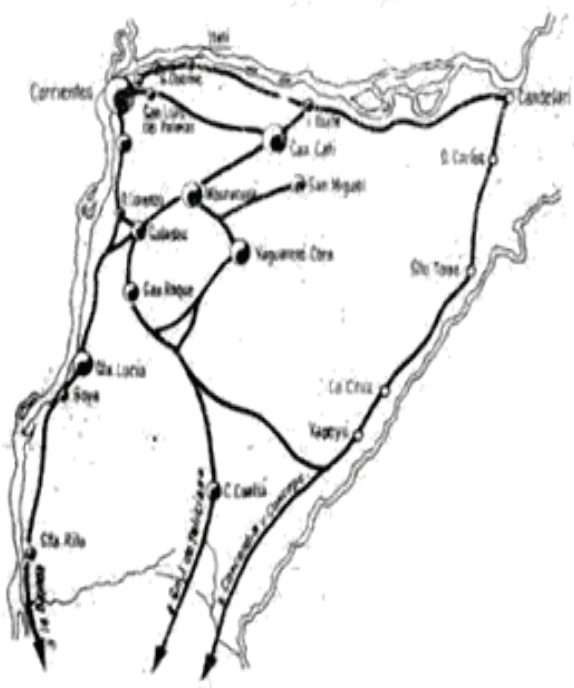

RED VIAL Y FERROVIARIA FINALES DEL S. XIX

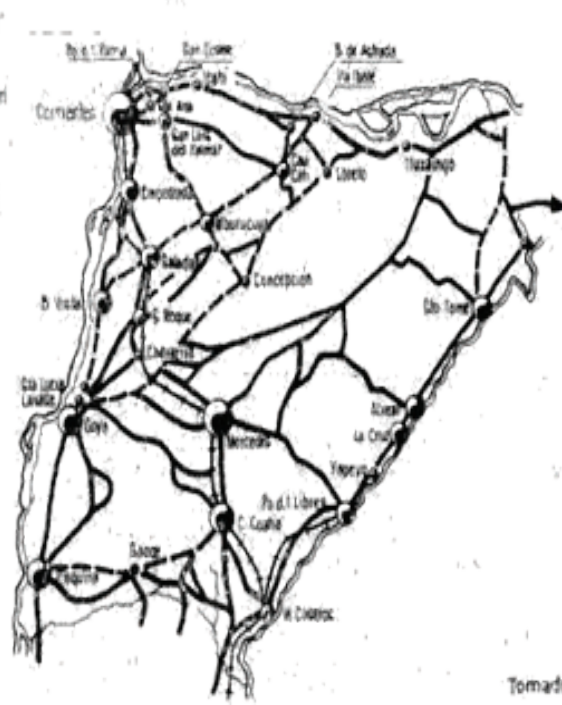

RED VIAL ACTUAL

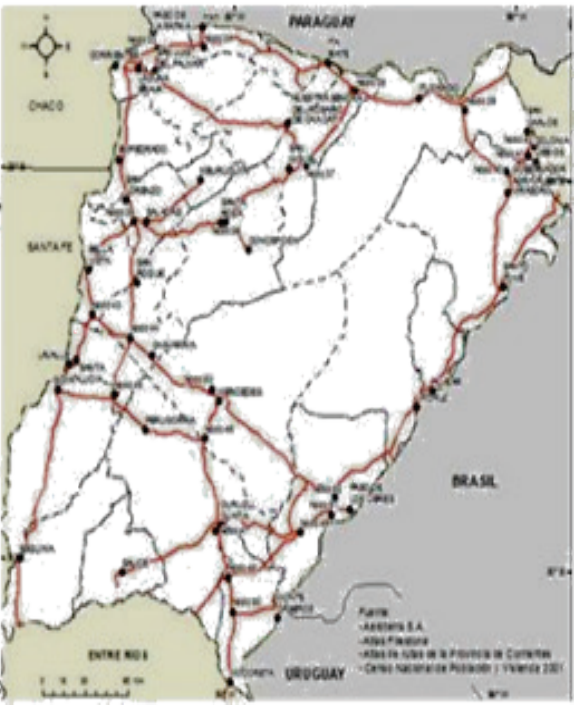

La estructura vial actual se organiza sobre la red de caminos reales, y si bien fue aumentando la conectividad a lo largo de los periodos analizados, mantiene la configuración de la red vial de fines del siglo XIX. 


\section{ETAPA DEL MODELO AGRO-EXPORTADOR (1880-1930)}

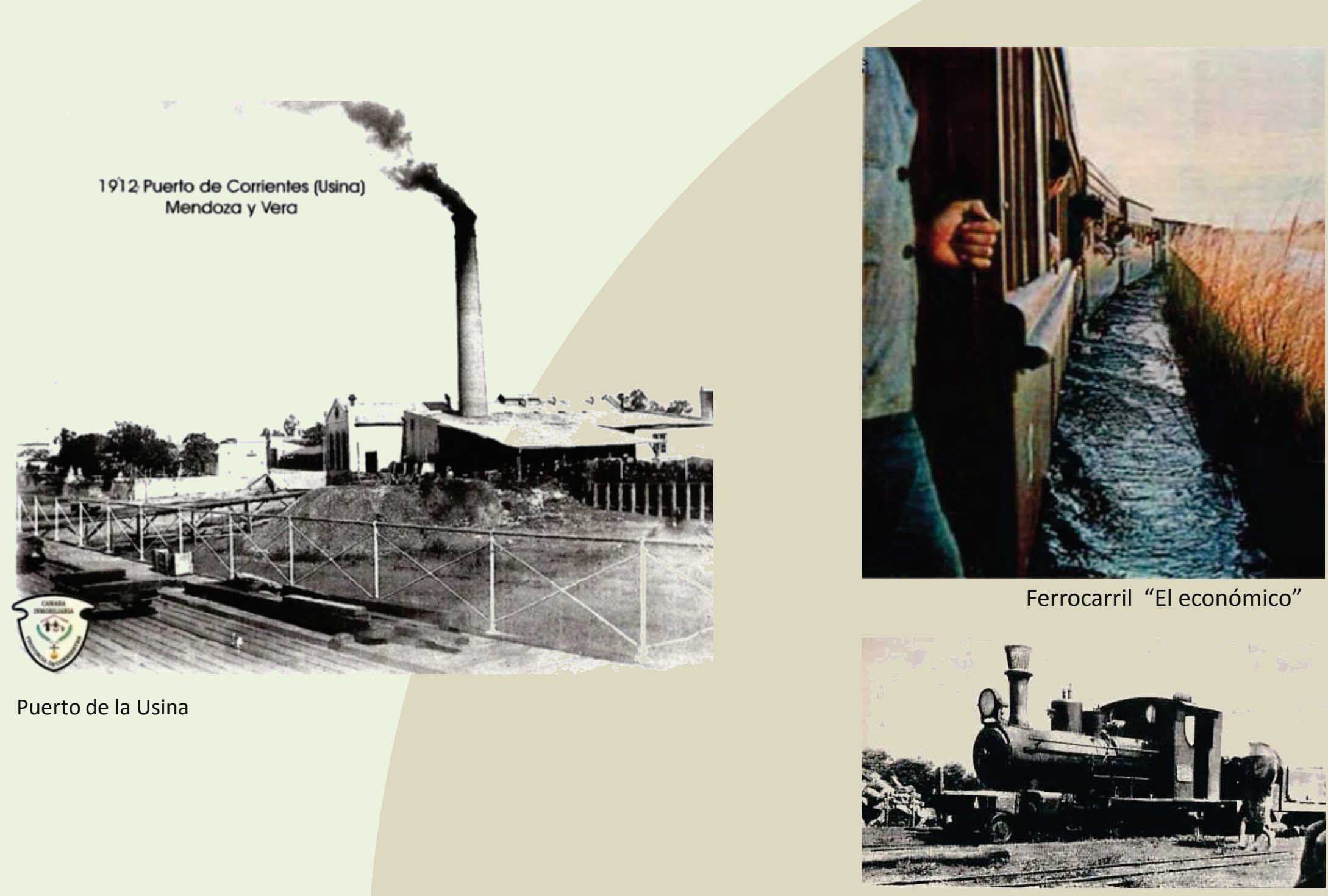

Publicado en formato digital: Arq. Silvina López; Ing. Guillermo Antonio Arce; Prof. Dr. Jorge Alfredo Alberto, Becaria Maria Florencia Medrano. PROCESOS TERRITORIALES RELACIONADOS CON LA EXPANSIÓN URBANA. MOVIMIENTOS DE POBLACIÓN Y DESPLAZAMIENTO DE USOS PRODUCTIVOS EN EL GRAN CORRIENTES. Revista Geográfica Digital. IGUNNE. Facultad de Humanidades. UNNE. Año 13. № 26. Julio - Diciembre 2016. ISSN 1668- 5180 Resistencia, Chaco. En: http://hum.unne.edu.ar/revistas/geoweb/default.htm 


\section{ANÁLISIS COMPARATIVO DE CADA EJE SEGÚN ESCALAS ESPACIAL Y TEMPORAL}

\begin{tabular}{|c|c|c|c|c|c|}
\hline $\begin{array}{l}\text { Eje de } \\
\text { análisis }\end{array}$ & $\begin{array}{c}\text { Periodo colonial - } \\
1879\end{array}$ & $\begin{array}{l}\text { modelo agro-exportador } \\
\qquad 1880-1930\end{array}$ & $\begin{array}{c}\text { modelo de } \\
\text { industrialización } 1930 \text { - } \\
1975\end{array}$ & $\begin{array}{l}\text { modelo rentístico- } \\
\text { financiero } \\
1976-2001\end{array}$ & 2002 - actualidad \\
\hline \multirow{3}{*}{ 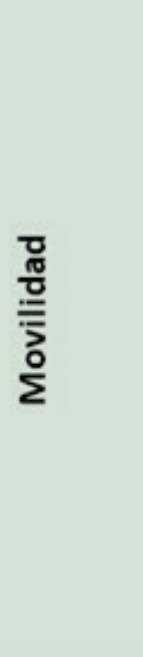 } & \multirow{3}{*}{$\begin{array}{l}\text { La ciudad Capital es } \\
\text { cabecera de un } \\
\text { amplio territorio } \\
\text { jurisdiccional. El } \\
\text { puerto adquiere una } \\
\text { gran jerarquía por los } \\
\text { intercambios } \\
\text { comerciales }\end{array}$} & \multicolumn{4}{|c|}{ La producción se traslada al mercado de Capital para su comercialización } \\
\hline & & $\begin{array}{l}\text { El ferrocarril económico } \\
\text { facilita el flujo de bienes y } \\
\text { personas entre las }\end{array}$ & $\begin{array}{l}\text { Los flujos entre las } \\
\text { localidades disminuyen } \\
\text { por el cese del ferrocarril }\end{array}$ & $\begin{array}{l}\text { Se incrementa el flujo de } \\
\text { bienes y servicios de la } \\
\text { capital con los municipios }\end{array}$ & $\begin{array}{l}\text { La movilidad diaria } \\
\text { aumenta por la } \\
\text { creciente dependencia }\end{array}$ \\
\hline & & localidades. & $\begin{array}{l}\text { La conectividad de las } \\
\text { localidades con la Capital } \\
\text { mejora por la } \\
\text { pavimentación de la } \\
\text { RN12 }\end{array}$ & $\begin{array}{l}\text { vecinospor la } \\
\text { pavimentación de rutas y } \\
\text { accesos a las localidades. }\end{array}$ & $\begin{array}{l}\text { de empleos en las } \\
\text { localidades en el } \\
\text { comercio y la } \\
\text { administración pública }\end{array}$ \\
\hline 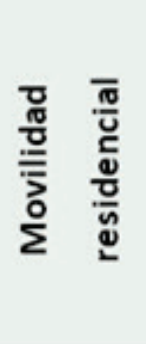 & & & & & $\begin{array}{l}\text { Familias de la Capital } \\
\text { se radican en } \\
\text { urbanizaciones en } \\
\text { Santa Ana, San } \\
\text { Cayetano y Riachuelo }\end{array}$ \\
\hline
\end{tabular}

Publicado en formato digital: Arq. Silvina López; Ing. Guillermo Antonio Arce; Prof. Dr. Jorge Alfredo Alberto, Becaria Maria Florencia Medrano. PROCESOS TERRITORIALES RELACIONADOS CON LA EXPANSIÓN URBANA. MOVIMIENTOS DE POBLACIÓN Y DESPLAZAMIENTO DE USOS PRODUCTIVOS EN EL GRAN CORRIENTES. Revista Geográfica Digital. IGUNNE. Facultad de Humanidades. UNNE. Año 13. № 26. Julio - Diciembre 2016. ISSN 1668- 5180 Resistencia, Chaco. En: http://hum.unne.edu.ar/revistas/geoweb/default.htm 
La ciudad Capital concentra el crecimiento poblacional con escasa entidad poblacional $y$ funcional del sistema de asentamientos de su área de influencia directa.

La estructura vial actual se organiza sobre la red de caminos reales (trazas del territorio colonial) y que se mantiene a finales del S. XIX condicionando y acentuando la conformación de un incipiente proceso de metropolización. los sistemas productivos

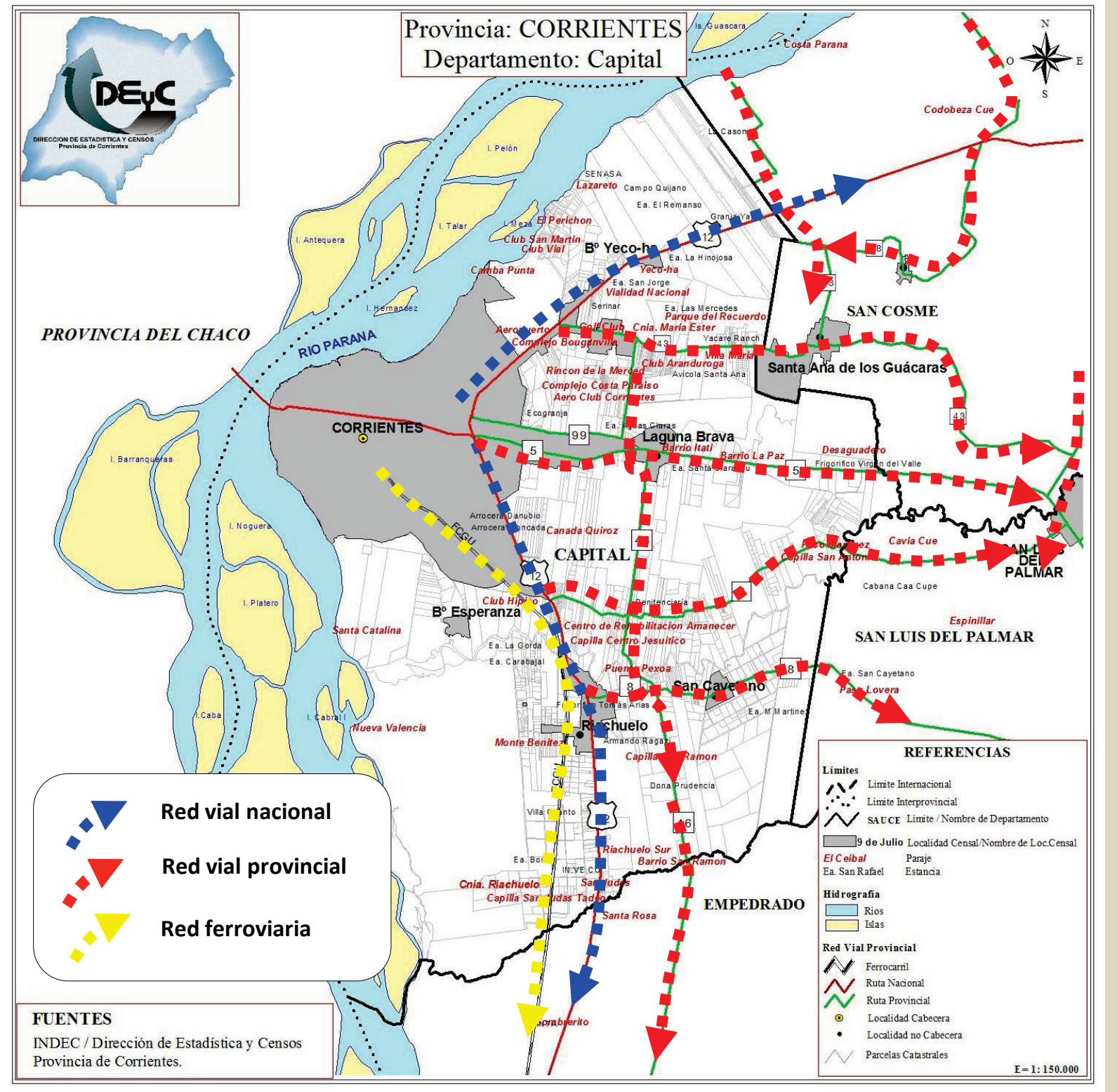

Publicado en formato digital: Arq. Silvina López; Ing. Guillermo Antonio Arce; Prof. Dr. Jorge Alfredo Alberto, Becaria Maria Florencia Medrano. PROCESOS TERRITORIALES RELACIONADOS CON LA EXPANSIÓN URBANA. MOVIMIENTOS DE POBLACIÓN Y DESPLAZAMIENTO DE USOS PRODUCTIVOS EN EL GRAN CORRIENTES. Revista Geográfica Digital. IGUNNE. Facultad de Humanidades. UNNE. Año 13. № 26. Julio - Diciembre 2016. ISSN 1668- 5180 Resistencia, Chaco. En: http://hum.unne.edu.ar/revistas/geoweb/default.htm 


\section{Emprendimientos productivos e inmobiliarios en Área de influencia directa Ciudad Capital}

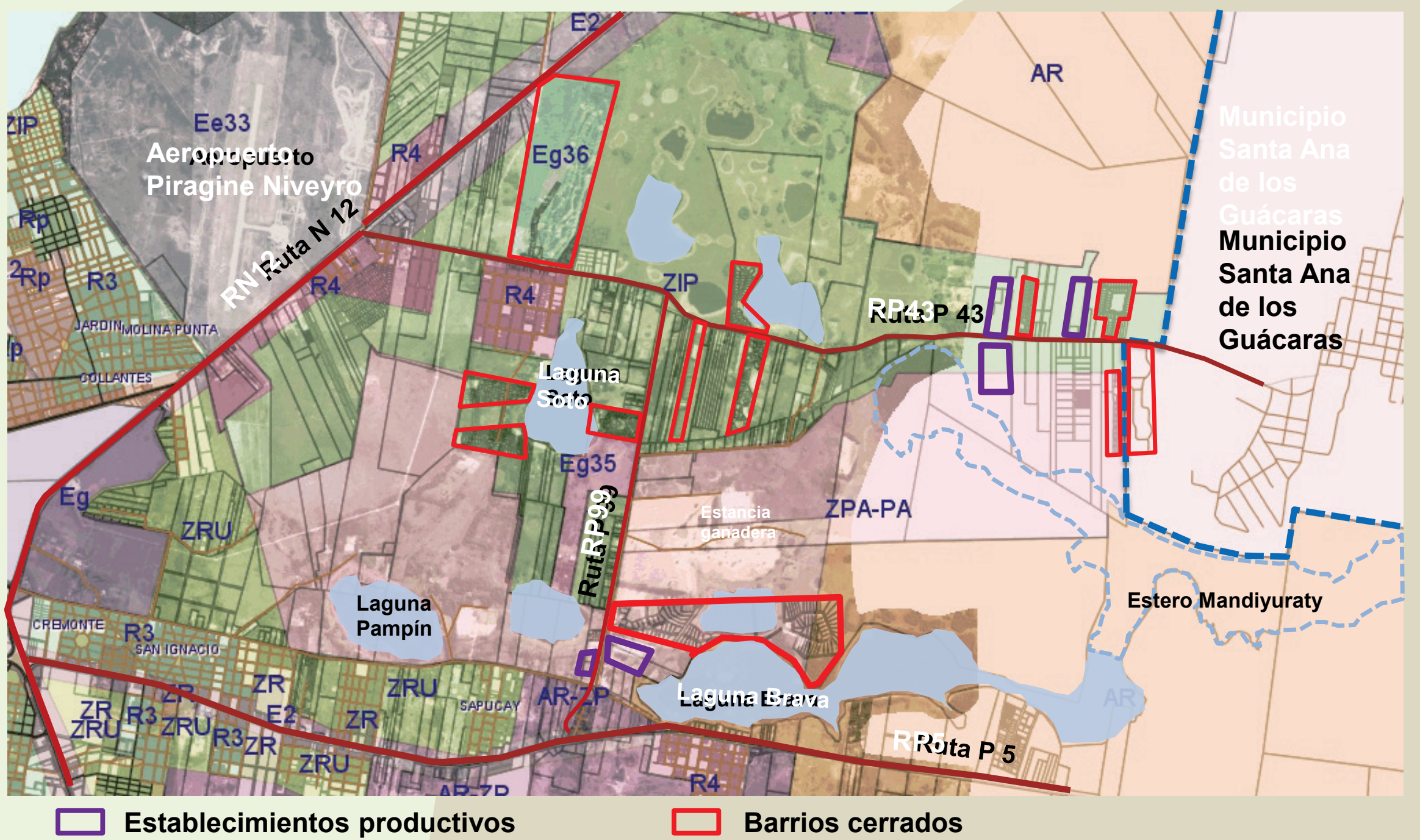

Fuente: Elaboración propia con base en SIG Municipalidad Ciudad de Corrientes.

Publicado en formato digital: Arq. Silvina López; Ing. Guillermo Antonio Arce; Prof. Dr. Jorge Alfredo Alberto, Becaria Maria Florencia Medrano. PROCESOS TERRITORIALES RELACIONADOS CON LA EXPANSIÓN URBANA. MOVIMIENTOS DE POBLACIÓN Y DESPLAZAMIENTO DE USOS PRODUCTIVOS EN EL GRAN CORRIENTES. Revista Geográfica Digital. IGUNNE. Facultad de Humanidades. UNNE. Año 13. № 26. Julio - Diciembre 2016. ISSN 1668- 5180 Resistencia, Chaco. En: http://hum.unne.edu.ar/revistas/geoweb/default.htm 


\section{CONDICIONES DE VIDA DE LA POBLACIÓN EN EL ÁREA}

Necesidades básicas insatisfechas (NBI):

Corrientes Capital presenta los mejores indicadores de condiciones de vida de la población del área en estudio.

El municipio Capital tiene un $\mathbf{1 7 , 4 \%}$ de hogares con NBI, mientras la provincia de Corrientes el $24 \%$,

En los municipios del área analizada los valores superan ampliamente a los provinciales: Riachuelo tiene el $\mathbf{3 0 , 9 \%}$ y Santa Ana el $\mathbf{2 7 , 0} \%$ de hogares con NBI. (INDEC, 2010).

Índice de Desarrollo Humano (IDH) :

La provincia de Corrientes presenta un valor de 0,794 , inferior al del promedio País 0,812

Ciudad Capital IDH 0,749, marcadamente superior a los municipios del área analizada:

Paso de la Patria 0,662,

Santa Ana 0,558;

San Cosme 0,588;

Riachuelo 0,491;

y con los valores más bajos:

San Luis del Palmar 0,454 y finalmente Herlitzka 0,010.

Cuanto más cercano a 1,00 sea el nivel alcanzado por el índice, mejor será el nivel de desarrollo humano. PNUD Índice de Desarrollo Humano 2006. 


\section{ALGUNAS OBSERVACIONES}

Población: A partir del período correspondiente al modelo agro exportador y hasta la actualidad la Ciudad Capital representa un significativo porcentaje de la población de la zona de estudio.

Actividades: La Ciudad Capital se convierte en sede administrativa desde los primeros años de vida independiente del país. El área de influencia directa tiene como principal actividad la agropecuaria minifundista y familiar desde el período agro exportador hasta la fecha. Paso de la Patria y Santa Ana incorporan nuevas actividades productivas, turísticas, inmobiliarias y recreacionales a partir del período rentístico financiero.

Conectividad: Si bien la red ferroviaria y vial ha crecido en forma sostenida desde el período agro exportador a la fecha mejorando la conectividad de los asentamientos, la declinación y abandono del ferrocarril implicó un retroceso del grado de conectividad que ha ido superándose con dificultad a través de la red vial hasta alcanzar un grado de conectividad media.

Movilidad: Se halla condicionada por la conectividad y actividades de interdependencia entre asentamientos. La producción se traslada al mercado de Capital para su comercialización. A partir de las nuevas jerarquías y servicios de la Capital (sede comercial, financiera, de centros de salud) se manifiestan nuevas causas de intercambio y movilidad.

En la actualidad se viene incrementando la Movilidad Residencial como fenómeno indicativo de un proceso incipiente de metropolización de la zona de estudio 


\section{REFLEXIONES FINALES} LA EXPANSIÓN URBANA. MOVIMIENTOS DE POBLACIÓN Y DESPLAZAMIENTO DE USOS PRODUCTIVOS EN EL GRAN CORRIENTES. Revista Geográfica Digital. IGUNNE. Facultad de Humanidades. UNNE. Año 13. № 26. Julio - Diciembre 2016. ISSN 1668- 5180 Resistencia, Chaco. En: http://hum.unne.edu.ar/revistas/geoweb/default.htm 


\section{REFLEXIONES FINALES}

La configuración actual del territorio y del sistema urbano, tal como lo plantea Santos, se originó en la estructura del territorio colonial y fue condicionada por la misma y por su rol marginal en los esquemas posteriores de organización política y espacial del territorio argentino.

Los indicadores de condiciones de vida de la población tan marcadamente diferentes entre la Capital y las localidades del área evidencian desigualdades y pueden explicar en parte los impactos generados por el crecimiento de la ciudad Capital en detrimento de la calidad socio ambiental de su entorno.

El análisis pone de manifiesto la necesidad de construir geoindicadores específicos que evidencien los fenómenos de ocupación y movilidad en el espacio interurbano y que permitan visibilizar la configuración incipiente de procesos de metropolización.

Con base en el análisis realizado en este trabajo, los indicadores deberían dar cuenta de las entidades poblacionales y funcionales como manifestación de dimensión espacial, pero además la historicidad de dichas entidades para atender a la dimensión temporal. 


\section{BIBLIOGRAFÍA CONSULTADA}

- Alberto, J. A. (2012) "Papel de los geoindicadores en el análisis espacial. Una herramienta de apoyo a la ciencia geográfica". En: Geográfica Digital. Año 9. № 17. UNNE. http://hum.unne.edu.ar/revistas/geoweb/default.htm

- Ávila Sánchez, H. Coordinador. (2005) "Lo urbano-rural, ¿nuevas expresiones territoriales? “Cuernavaca: UNAM, Centro Regional de Investigaciones Multidisciplinarias.

- Benedetti, A. (2011); coordinado por Patricia Souto. "Territorio, lugar, paisaje: prácticas y conceptos básicos en geografía". la ed.- Buenos Aires: Editorial de la Facultad de Filosofía y letras Universidad de Buenos Aires. pp. 288.

- Capel, H. (1994) "Las periferias urbanas y la geografía. Reflexiones para arquitectos". Barcelona: En Capel H. La geografía hoy. Textos, historia y documentación. Barcelona: Anthropos, № 43.

- Feria, J.M. (2011) "Ciudad y territorio: nuevas dinámicas espaciales" en PUJADAS, I. et al. (Eds.): Población y Espacios urbanos. Barcelona: Departament de Geografia Humana de la UB y Grupo de Población de la AGE.

- Foschiatti, A.M.(2013) "CENSO 2010. Corrientes. Indicadores Demográficos". Geográfica Digital. Año 10. №19. UNNE. Chaco. En: http://hum.unne.edu.ar/revistas/geoweb/default.htm.

- Gutiérrez, R, Sánchez Negrette, A. (1988) “Evolución urbana y arquitectónica de Corrientes”. Instituto Argentino de Investigaciones en Historia de la Arquitectura y el Urbanismo.

- INDEC. Censos Nacionales de Población Argentina: Censo Nacional. 1895. En: http://www.deyc-corrientes.gov.ar/files_provincias/419.pdf . Censo Nacional. 1914. pp. 249 - 261. En: ttp://www.deie.mendoza.gov.ar/tematicas/censos/censos_digitalizados/Censos\%20Digitalizados/index.html . Censo General de la Nación. 1947. pp 200 - 226 En: http://www.deyc-corrientes.gov.ar/tema/204-censo-nacional-de-poblacion-1947.html . Censo Nacional de Población 1960. En: http://www.deyc-corrientes.gov.ar/tema/205-censo-nacional-de-poblacion-1960.html. Censo Nacional de Población, Hogares y Vivienda. Argentina. 2010. En: http://www.censo2010.indec.gov.ar/

- Lindenboim, J y Kennedy,D. (2004) "Dinámica urbana Argentina. 1960-2001. Reconstrucción y análisis de la información necesaria". Doc. De Trabajo №3, CEPED. En:http://bibliotecavirtual.clacso.org.ar/Argentina/ceped-uba/20110516103448/DT3_Linde nboim_Kennedy.pdf

- López, S; Arce, G.(2015). "Contribución de las encuestas de movilidad domiciliaria al análisis de la movilidad urbana. EOD aplicada al Gran Corrientes". Revista Geográfica Digital. IGUNNE. Facultad de Humanidades. UNNE. Año 12. №24. Julio - Diciembre 2015. ISSN1668-5180. Rcia, Chaco. En: http://hum.unne.edu.ar/revistas/geoweb/default.htm

- López, S, Arce, G., Alberto, J. (2015)“Indicadores de desarrollo sostenible para espacios sujetos a la presión del crecimiento urbano. Santa Ana de los Guácaras Corrientes". Revista Geográfica Digital. IGUNNE. UNNE. Año 2015. № 23. Resistencia, Chaco.

- Maeder, E. (1986) “La formación de la economía correntina (siglos XVI a principios del XIX)”. Revista Todo Es Historia, Capítulo 5. Buenos Aires.

- Méndez, P y López; M. (1994) . “Corrientes, sus planes reguladores y otros escritos”. UNNE 
- Ministerio de Planificación Federal, Inversión Pública y Servicios (2011) “Plan Estratégico Territorial Avance Il: planificación estratégica territorial. Proceso de planificación estratégica conducido por el Gobierno Nacional, mediante la formación de consensos, para el despegue de la inversión pública y el desarrolla territorial". 1a ed. - Buenos Aires: Ministerio de Planificación Federal, Inversión Pública y Servicios. pp 114.

- Ministerio de Planificación Federal, Inversión Pública y Servicios (2011) “Plan Estratégico Territorial Avance Il: planificación estratégica territorial. Territorio e infraestructura. Actualización del modelo territorial deseado/identificación estratégica y ponderación de proyectos". 1a ed. - Buenos Aires: Ministerio de Planificación Federal, Inversión Pública y Servicios. pp 246.

- Ministerio de Planificación Federal, Inversión Pública y Servicios (2011) “Plan Estratégico Territorial Avance II: planificación estratégica territorial. Argentina urbana. Lineamientos estratégicos para una política nacional de urbanización". 1a ed. - Buenos Aires: Ministerio de Planificación Federal, Inversión Pública y Servicios. pp. 180.

- Ministerio de Planificación Federal, Inversión Pública y Servicios (2011) “Plan Estratégico Territorial Avance II: planificación estratégica territorial. Integración territorial internacional. Planes, programas y proyectos para la consolidación de la integración regional”. 1a ed. - Buenos Aires: Ministerio de Planificación Federal, Inversión Pública y Servicios. pp. 190.

- Novacovsky, I y Bustos, J. (2005) Estudio de base Provincia de Corrientes. Informe Final

- Oszlak, Oscar (1997) "La formación del estado argentino". Buenos Aires, Planeta.

- Perez, Maria E. (1984). "La red vial y las comunicaciones terrestres en Corrientes. Origen y evolución. 1588-1898”. Cuadernos de Geohistoria Regional N¹0. Instituto de Investigaciones Geohistóricas. Resistencia, Conicet-Fundanord. 169 p.

- Ministerio de Planificación Federal, Inversión Pública y Servicios (2008) "1816 -2016. Argentina del Bicentenario. Plan Estratégico Territorial. Avance 2008. Buenos Aires: Ministerio de Planificación Federal, Inversión Pública y Servicios.

- Popolizio, E. (1989) “Algunos elementos geomorfológicos condicionantes de la organización espacial y las actividades del NEA", Geociencias № XVII. UNNE, Resistencia, Chaco.

- Rapoport, Mario. 2006. “Etapas y crisis en la historia económica argentina: 1880-2005”. En: Oikos N²1, Santiago de Chile, EAE, Universidad Católica Silva Henríquez (UCSH), pp 55-88.

- Rial, E. 1985. "La Reducción de Santa Ana de los Guácaras". En: Historia de los Correntinos y de sus pueblos, Revista N³.

- Sánchez Negrette, Angela. 1995. Tren "El Económico" su gravitación en los poblados correntinos. Centro de Estudios históricos, arquitectónicos y Urbanos, FAU-UNNE. CICERO impresiones. Corrientes.

- Santos, Milton. 1990. Por una geografía nueva. Madrid, Espasa-Calpe. S.A. 